\title{
O ENSINO DA MECÂNICA HIDRÁULICA A PARTIR DE MAQUETES DE MÁQUINAS AGRÍCOLAS
}

\section{THE TEACHING OF HYDRAULIC MECHANICS FROM AGRICULTURAL MACHINERY MACHINES}

Victoria Regina Franco de Leão ${ }^{1}$; Willian Felipe Souza Fonseca ${ }^{2}$; Carlos de Souza Carvalho³; Pablo Radamés Cabral de França ${ }^{3}$

DOI: https://doi.org/10.31692/978-65-991061-7-0.474-477

\section{INTRODUÇÃO}

Com o crescimento da atividade agrícola, surgiu a necessidade da criação de novos mecanismos que pudessem aumentar o rendimento do trabalhador no campo. Com a revolução industrial o aumento da população demandava cada vez mais alimentos, gerando a necessidade de aumentar a produtividade agrícola para suprir a necessidade de subsistência. Tornando necessário o desenvolvimento tecnológico no campo (LOCH et al., 2016).

A implantação de novos mecanismos agrícolas dentre eles o sistema hidráulico promove a diminuição da exposição do trabalhador aos perigos do trabalho e maior eficiência na produção e reduz os custos e perdas no campo, sua versatilidade permite que seja aplicado das mais variadas formas nos implementos agrícolas.

Assim é importante que esse mecanismo seja apesar de simples em seu funcionamento e aplicação, seja bem compreendido e que novas formas de sua aplicabilidade sejam pensadas. Além disso é necessário que esse mecanismo seja bem trabalho sobretudo por pessoas que possuem um contato mais direto com ele, como os trabalhadores do campo aumentando os rendimentos com o seu uso adequado e evitando possíveis acidentes de trabalho.

\section{RELATO DE EXPERIÊNCIA}

O trabalho foi desenvolvido na disciplina de Mecanização Agrícola do curso de Agronomia do IFPA- Campus Castanhal, e teve como objetivo demonstrar de forma prática o funcionamento do sistema hidráulico das máquinas agrícolas, cujo mecanismo observado foi através de uma maquete confeccionada pelos discentes, no qual utilizaram materiais alternativos como seringas descartáveis e mangueiras de soro para representar o sistema hidráulico.

De acordo com Pitano e Roqué (2015) a utilização de maquetes promove ao

${ }^{1}$ Enga Agronômica, IFPA- Campus Castanhal, alamedaafua20@gmail.com

${ }^{2}$ Eng $^{\mathrm{a}}$ Agronômica, IFPA- Campus Castanhal, will.agronomia2015@gmail.com

${ }^{3}$ Eng $^{a}$ Agronômica, IFPA- Campus Castanhal, andersom casc@ hotmail.com

33-Doutor em Agronomia, IFPA - Campus Castanhal, pablo.radames@ifpa.edu.br 
observador compreendê-lo a partir da visualização e manipulação, pois representa o objeto em uma escala menor, porém nas três dimensões, seja com fins de estudo, artístico, planejamento ou comercial. Quando à relacionamos com o estudo, promove uma maior interação do discente com o docente, facilitando a compreensão do assunto. o uso de práticas pedagógicas interdisciplinares na sala de aula, não somente na educação básica, mas também no Ensino Superior, proporciona aos alunos ampliarem sua capacidade de percepção e de análise dos fenômenos relacionados aos diversos campos do saber.

A escolha do uso dos materiais foi determinada pelo professor, com o intuito de diminuir os custos da atividade e pelo fato de apresentarem condições parecidas com as encontradas nos sistemas hidráulicos utilizados nas máquinas agrícolas e por permitir uma observação mais efetiva do sistema em funcionamento. O professor deixou à critério de cada grupo a escolha da máquina ou equipamento que seria representado para demonstração do princípio de funcionamento do pistão hidráulico. Dessa forma, escolheu-se para a montagem da maquete uma prensa de algodão, na qual foram usadas duas seringas, sendo uma de $10 \mathrm{ml}$ e outra de $20 \mathrm{ml}$, além de mangueiras de soro, madeira e resina sintética conhecida como baquelite, sendo estes materiais de baixo custo.

O funcionamento da maquete teve como base o Princípio de Pascal onde "O acréscimo de pressão produzido em um líquido em equilíbrio transmite-se integralmente a todos os pontos do líquido" (SANTOS, 2018), representada pela seguinte relação (TODAMATÉRIA, 2018):

$$
\frac{F 1}{A 1}=\frac{F 2}{A 2}
$$

\section{Onde:}

F1 e F2 = forças aplicadasA1 e A2 = áreas dos êmbolos

A estrutura da prensa hidráulica (Imagem 1 e 2 ) foi construída em madeira (compensado) e para facilitar a ação do processo de prensagem foi colocado na parte frontal da mesma uma placa de baquelite transparente. Em seguida foram colocadas as seringas posicionando-as seguindo as recomendações para a montagem, por meio de um estudo prévio. 


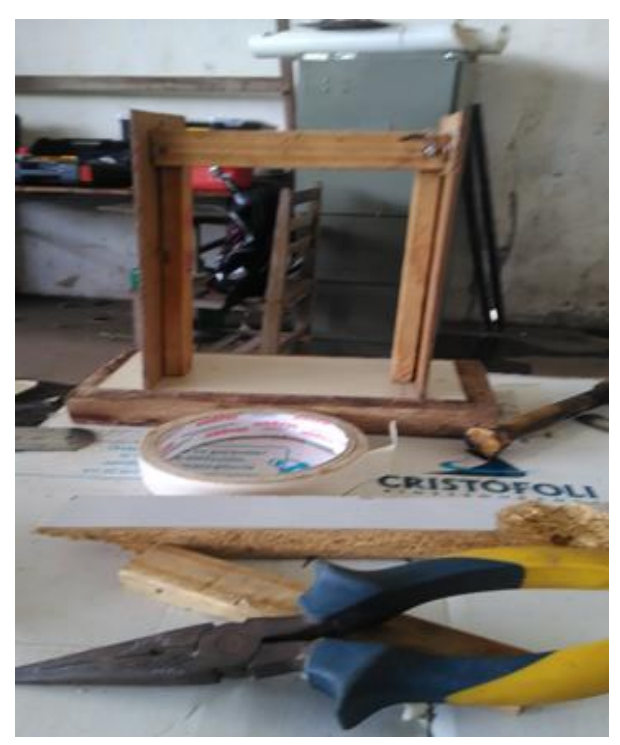

Imagem 1: Confecção da prensa

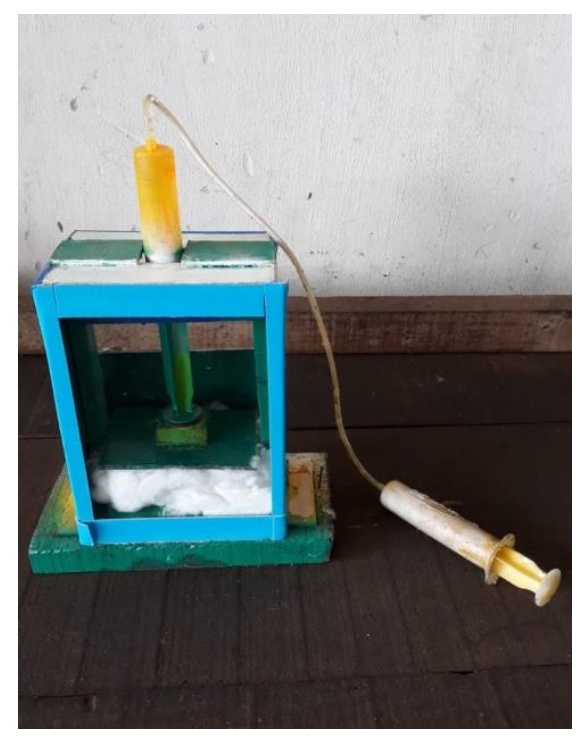

Imagem 2: Maquete finalizada da prensa de algodão

A escolha de uma seringa de $10 \mathrm{~mm}$ e outra de $20 \mathrm{~mm}$ foi para demonstrar que ao acionar uma seringa menor irá deslocar a seringa maior, sem maior esforço. Isso ocorre devido a transmissão integral do líquido para a segunda seringa, independente da área, o que permite, em termos práticos, prensar a fibra de algodão para produzir fardos de $90 \mathrm{Kg}$ (exemplo utilizado para representação da maquete) a partir do acionamento manual de uma alavanca.

Após a confecção e realizado os testes com a maquete, a mesma foi apresentada em sala de aula para a turma de Agronomia 2016 (semestre 2018.1) sendo demonstrado, além do Princípio de Pascal, a aplicação do mesmo na prensa hidráulica, assim como o princípio de funcionamento.

Posteriormente, foi apresentada para a Instituição e para a comunidade externa durante uma feira de ciências realizado no campus, onde o projeto foi exposto para alunos de várias escolas e pessoas de comunidades locais e de municípios vizinhos que participaram do evento. Assim, puderam observar na prática como ocorre o funcionamento de um sistema hidráulico de uma forma simples e didática, além de esclarecerem dúvidas quanto ao funcionamento do sistema e das máquinas onde pode ser empregado. A forma como o mecanismo atua na prensa de algodão, por ser simples dentre outras formas de aplicação, serve de base para utilização em outros sistemas de mecânica hidráulica, voltados para o funcionamento de implementos agrícolas. Com a maquete isso permitiu uma compreensão maior do público acerca de como o sistema funciona e suas aplicações. 


\section{CONSIDERAÇÕES}

Com o desenvolvimento da maquete da prensa de algodão foi possível ter um conhecimento mais prático e efetivo em relação ao funcionamento do sistema hidráulico nas máquinas agrícolas, a forma como ele ocorre dentro da máquina e como ele pode ser empregado das mais variadas formas e finalidades. A utilização das seringas para a construção evidenciou ainda mais a versatilidade deste tipo de sistema dado a praticidade dos materiais e a facilidade para a montagem da prensa, além disso a possibilidade de trocar informações entre os discentes e de repassar o conhecimento para a comunidade permitiu uma interação e formação de saberes muito maior do que poderiam ser obtidos da maneira convencional de ensino.

Assim, considerando o custo com a produção da maquete, no caso que foi quase nulo, devido ao uso de materiais alternativos e o tempo gasto para sua confecção fica evidente que a metodologia de ensino empregada é altamente viável pois permite não apenas o aprendizado dos discentes envolvidos mas da comunidade como um todo, já que se torna parte do processo de disseminação do conhecimento ao participar da atividade.

\section{REFERÊNCIAS}

LOCH, M.; CASTRO, M.R.; PERUCH, J.F.; HELENA, S.C.; SEPULVEDA, F. Projeto Conceitual da Estrutura Mecânica para Testes do Sistema Hidráulico do Levante de Máquinas Agrícolas. Revista Ciência e Tecnologia, v. 19, n. 34, p. 57 - 62, 2016.

PITANO, S.C.; ROQUÉ, B.B. O uso de maquetes no processo de ensino-aprendizagem segundo licenciandos em Geografia. Educação Unisinos, v. 19, n. 2, p. 273-282, 2015.

SANTOS, M.A.S. Máquinas Hidráulicas: A Aplicação do Princípio de Pascal. Brasil Escola. Disponível em <https://brasilescola.uol.com.br/fisica/maquinas-hidraulicas-aplicacaoprincipio-pascal.htm>. Acesso em 24 de setembro de 2018.

TODAMATÉRIA. Princípio de Pascal. Disponível em https://www.todamateria.com.br/principio-de-pascal/. Acesso em 24 de setembro de 2018.

VEIT, A.A; ALONÇO, A.S; FRANCETTO, T.R; BECKER, R.S; BELLÉ, P.M. Capacidade do sistema de levante hidráulico dos tratores agrícolas de pneus no Brasil. Tecno-Lógica, Santa Cruz do Sul, v. 20, n. 1, p. 55-61, 2016. 